\title{
Hazard and Operability Analysis(HAZOP) of a Plastic Manufacturing Plant at Karachi, Pakistan.
}

\author{
Shagufta Ishtiaque ${ }^{1}$, Sidra Sikandar $^{2}$, Muhammad Faisal Akhter ${ }^{1}$ \\ , Mehwish Altaf ${ }^{1}$, Mohammad Siddique $^{3}$ \\ 1-Department of Chemical Engineering, University of Karachi \\ 2-Department of Integrated Sciences and Mathematics, Habib University, Karachi, Pakistan. \\ 3-Department of Chemical Engineering, BUITEMS, Quetta, Pakistan \\ Corresponding Author: shaguftai@uok.edu.pk
}

\begin{abstract}
The basic objective of this study is to analyze the hazards and operational problems of plastic manufacturing plant and provide some recommendation to operate plant in a hazard free environment. HAZOP technique is used to study the whole process of the unit from the storage Silos (Propylene) to Winding machine (collection point of plastic film). Initially eight (08) nodes were selected and analyzed qualitatively as per process flow diagram (PFD) and piping and instrumentation diagram (P\&IDs) of the plant. The analysis includes the deviation of the process parameters from the standard conditions, the causes of the deviation, the resulting consequences, and the existing safety measures and finally recommendations were suggested to avoid the damage and loss to equipment, product and personnel. Result shows 25 causes of deviations of process parameters, 19 consequences out of which $53 \%$ of the consequences were related to the product, $42 \%$ were related to the equipment and $5 \%$ were related to the surrounding and personnel. Moreover, about 11 different existing safety measures were installed and practiced by the company and 16 recommendations were suggested.
\end{abstract}

Keyword: HAZOP, plastic, packaging industry, consequences, deviation, and Polypropylene.

Date Received 13 May 2019

Date Accepted 27 June 2019

Date Published 5 July 2019

\section{INTRODUCTION:}

The working environment in any industry is shaped by many factors. Therefore almost every work is connected with the occupational risk that is associated with the probability of arrival of such undesirable events, as incidents or occupational disease (A.Kania et al, 2011).

According to occupational safety and health administration (OSHA); a hazard is a condition or a set of conditions that present a potential for harm. In order to stop any hazard, its identification is the elementary and primary step. If the hazard is not recognized, then risk assessment is not said occur. There are numerous methods of hazards identification which are applicable in different stages and phases whether design or execution phase in a chemical plant. (British Standard BS: IEC61882:2002 (2002) Hazard and operability studies (HAZOP studies)- Application Guide British Standards Institution, This British Standard reproduces verbatim IEC 61882:2001 and implements it as the UK national standard. 2001).

Several accidents could have been avoided if adequate process safety analysis have been done and this reflects the importance of safety analysis in process operation to ensure safe operation. Process Hazard analysis (PHA) is also very important to identify the potential hazards and suggest feasible mitigation action. Hazard and operability (HAZOP) analysis is the most widely used among several PHA techniques (S.Sikandar et al 2016).

A HAZOP study identifies hazards and operability 
problems. The concept involves analysing how the plant might deviate from the design intent. If, in the process of identifying problems during a HAZOP study, a solution becomes apparent, it is recorded as part of the HAZOP result; however, care must be taken to avoid trying to find solutions which are not so apparent, because the prime objective for the HAZOP is problem identification. Although the HAZOP study was developed to supplement experience based practices when a new design or technology is involved, its use has expanded to almost all phases of an industrial plant's life. HAZOP is based on the principle that several experts with different backgrounds can interact and identify more problems when working together than when working separately and combining their results. With the passage of time, increasing frequency of environmental hazards and human negligence can cause such hazards that cannot be fully rectified. Safety and risk management in industries of plastic sectors play a crucial role in preventing accidents. The important step is the design phase in risk management of any industry (Aspin all et al, 2006).

Another Hazop is Retrospective HAZOP which was considered suitable for safety assurance, but because of limitations and considerable time of the study it is rejected. The technique has been developed starting from Process Hazard Review and HAZOP. It was applied to a process of acrylic polymerization along the whole production cycle. The HAZOP study is carried out only to those sections of a plant where it has been determined that a deviation from the design intent could lead to serious accidents. (BorghiB.Fabiano, et al 2001), (Zhaoa, et al 2009)

HAZOP studies were carried out systematic way about 40 years ago where a multidisciplinary group used keywords on process variables to discover potential hazards and operational problems. (Calixto et al)

HAZOP consists of a detailed study of the whole industrial process from beginning to end with the help of variations in process conditions with respect to temperature, pressure, material or energy flows in piping and instrumentation diagram (P\&ID). One important factor to consider in HAZOP studies is the time required to implement the entire analysis. (Dunjo, et al 2010)

In this work HAZOP study was conducted for the case study of a Cast Polypropylene (CPP) film manufacturing unit of a plastic manufacturing company located at Karachi, Pakistan. This research attempts to introduce suitable method of HAZOP analysis for the given process in functional phase to identify any risk that might be a hazard for the unit and its surrounding environment. Also used to ensure safe operability of the CPP film manufacturing unit.

\section{METHODOLOGY}

Several techniques and methodologies for risk and safety assessment have been proposed since 1970 including HAZOP, fault tree analysis (FTA), Failure mode effect analysis (FMEA), What-if analysis, and other schemes based on a combination of various techniques. (Faisal I Khan et al 1998).

This methodology is based upon on the principle of traditional HAZOP studies which is based on the fact that a problem can only arise when there is a deviation from intended designprocess conditions. In most of the HAZOP study process has been studied by team members by deviding the process flow diagram/piping and instrumentation diagram into small sections or nodes(Netta Liin Rossinga et al 2009).

Similarly, the Plastic manufacturing company located in Karachi quantitatively analysed by HAZOP team members. Briefly Cast Polypropylene (CPP)plastic films were produced by extrusion casting method. Here Polypropylene granules with copolymers and additives enters from hopper into the extruder, melt at about $250 \mathrm{oC}$. The resulting melt then entered into the Die Plug (D-0001) to form a multi-layered film. After the die plug it is passed on the roller machine at $22 \mathrm{oC}$ to form specific shape. To increases the adhesion of surface it is passed to Corona Treatment unit. Finally, the finished CPP films were collected on winding machine and the winded rolls are placed on stacks for the aging process (Fig. 01).

To simplify $\mathrm{P}$ and ID nodes were identified on the basis of equipmentsof fig.01, which included granules feeding polypropylene (PP) Silos (S-01), Extruder (EXT-01), Die plug, Cast Roll (CR-01), Chill Roll (CR-02), Treatment Unit, Trimmer and Winder.

For the considered nodes the design's intended and normal operating conditions were specified (Jordi et al 2010). Later, the possible deviation in each process parameter such as flow, pressure and temperatures were identified with reference to suitable guide words (table1). All the possible causes and consequences of deviations were listed and concluded the HAZOP document with necessary recommendations to 
minimize or prevent the effects of the consequences(shagufta et al 2017)

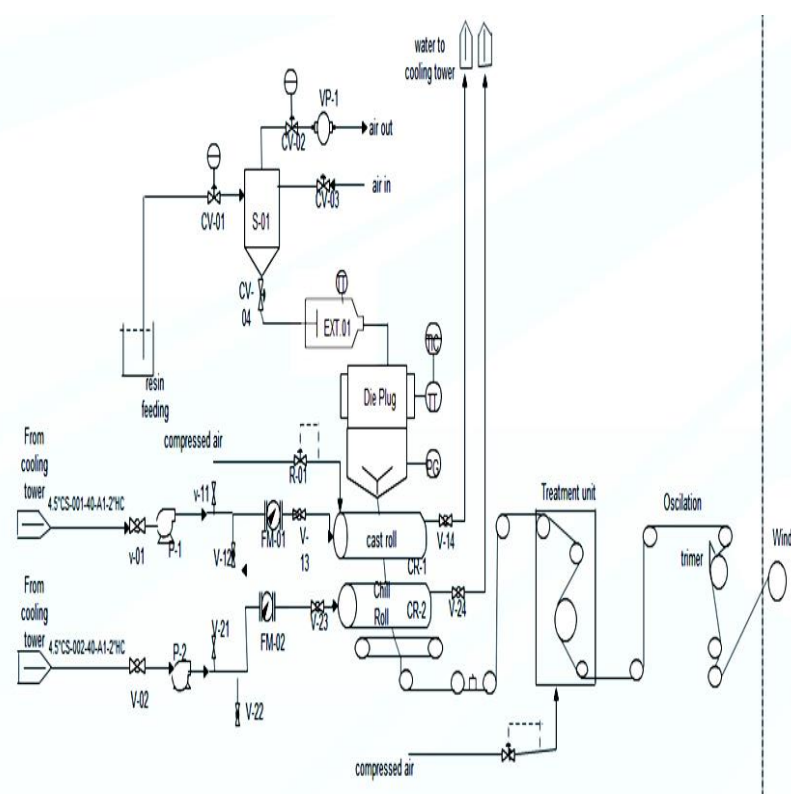

Figure 1:Process and Instrumentation Diagram of Plastic Manufacturing Unit

\begin{tabular}{|l|l|}
\hline Guide Words & Description \\
\hline NO or NOT & $\begin{array}{l}\text { Complete Negation of the } \\
\text { design intent }\end{array}$ \\
\hline MORE & $\begin{array}{l}\text { Quantitative increase } \\
\text { Quantitative decrease }\end{array}$ \\
\hline LESS & A Qualitative Increase \\
\hline AS WELL AS & A Qualitative decrease \\
\hline PART OF & $\begin{array}{l}\text { Logical Opposite } \\
\text { Intentions }\end{array}$ \\
\hline REVERSE & Complete Substitution \\
\hline OTHER THAN & \\
\hline
\end{tabular}

Table 1 Explanation of guide words with process to process parameters

\section{RESULT AND DISCUSSION:}

On the basis of above methodology of the technique, a detailed HAZOP analysis report (table 2) has been formulated. In which all operational problems were analyzed and more attention paid on the deviations with negative impact on the operations of the system resulting in financial losses and personal injuries.The deviation of process parameters such as temperature, pressure and flow from the standard process conditions were also recognized by using guide words such as no, lessetc usedthis study as presented in Table 1. Since result shows a single deviation of the process parameter from the standard conditions has several causes for it resulting in many consequences. In HAZOP sheet about 25 causes of deviation were identified. The causes were mostly related to equipment or machinery malfunction or blockage, of which the main causes included failure in temperature measurement instruments, malfunctioning of valves, failure in pump suction, high melt flow index of resin. This results in about 19 consequences, the more severe consequences may result in burst of pipe, damage to the extruder, no product output i.e. no plastic film production and may result in fire as well. Out of all consequences, $52 \%$ were predicted to affect the product in terms of its production and quality, $42 \%$ can affect the equipment and $5 \%$ of the surrounding environment including factory personnel may have an adverse effect. There are currently about 11 different existing safety control measures installed and practiced by the company. Some of which includes, Alarms indicating deviation of parameters such as temperature, pressure and flow, drain valves, control valves and a quality control lab for the identification of any impurity in raw material and product quality.

On the basis of detailed investigation about 16 suggestions / recommendations have been proposed in 
table 2. Suggestions were related to the modification and improvement of equipment and process such as installation of automatic flow alarms, installation of equipment non-return valves, control valves and regular maintenance of

Table2:Summarized HAZOP Sheet of Plastic Manufacturing Unit

\begin{tabular}{|c|c|c|c|c|c|}
\hline $\begin{array}{l}\text { Deviatio } \\
\text { n with } \\
\text { respect } \\
\text { to guide } \\
\text { word }\end{array}$ & $\begin{array}{c}\text { Process } \\
\text { parameters }\end{array}$ & Possible Causes & Consequences & $\begin{array}{c}\text { Existing Safety } \\
\text { control }\end{array}$ & $\begin{array}{c}\text { Recommended } \\
\text { Action }\end{array}$ \\
\hline No & Flow & $\begin{array}{l}\text { 1. Failure of } \\
\text { Valve (CV- } \\
\text { 01). } \\
\text { 2. No power } \\
\text { supply to } \\
\text { pump (P-1 \& } \\
\text { P-2) supplying } \\
\text { cooling water } \\
\text { to cast and } \\
\text { chill roll. } \\
\text { 3. Failure in } \\
\text { pump (P-1 \& } \\
\text { P-2) suction. } \\
\text { 4. Winding } \\
\text { Motor stop } \\
\text { working. }\end{array}$ & 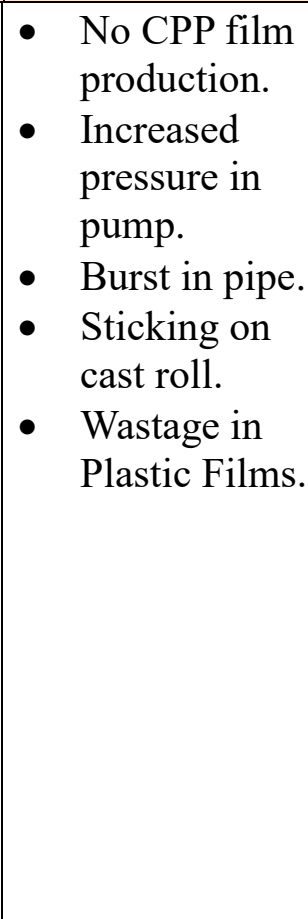 & \begin{tabular}{|l} 
Temperature \\
Transmitter \\
(TT) and \\
Temperature \\
Indicator \\
Controller \\
(TIC) \\
installed on \\
EXT-01 and \\
Die Plug \\
respectively. \\
Manual \\
control \\
valve (V-01 \\
\& V-02) \\
- Drain valve \\
(V-12 \& V- \\
21) also \\
available.
\end{tabular} & $\begin{array}{l}\text { a. Install automatic } \\
\text { flow control valve. } \\
\text { Along with water } \\
\text { flow alarm- } \\
\text { HIGH(FIAH) in } \\
\text { place of manual } \\
\text { valve. } \\
\text { b. Operator } \\
\text { training. } \\
\text { d. Tag meter } \\
\text { installation on } \\
\text { Winder. }\end{array}$ \\
\hline High & Temperature & $\begin{array}{l}\text { 1. Temperature } \\
\text { Sensor } \\
\text { dislocated } \\
\text { from different } \\
\text { zones of } \\
\text { Extruder } \\
\text { (EXT-01). }\end{array}$ & 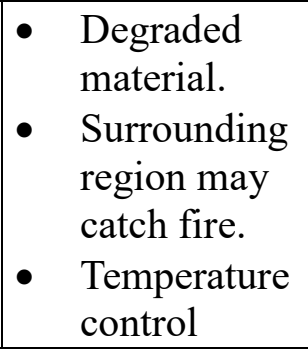 & \begin{tabular}{|l} 
Temperature \\
indicator \\
alarm \\
high(TIAH- \\
02)is also \\
exist
\end{tabular} & $\begin{array}{l}\text { a. } \\
\text { Periodic } \\
\text { maintenance and } \\
\text { calibration of } \\
\text { Sensor. }\end{array}$ \\
\hline
\end{tabular}




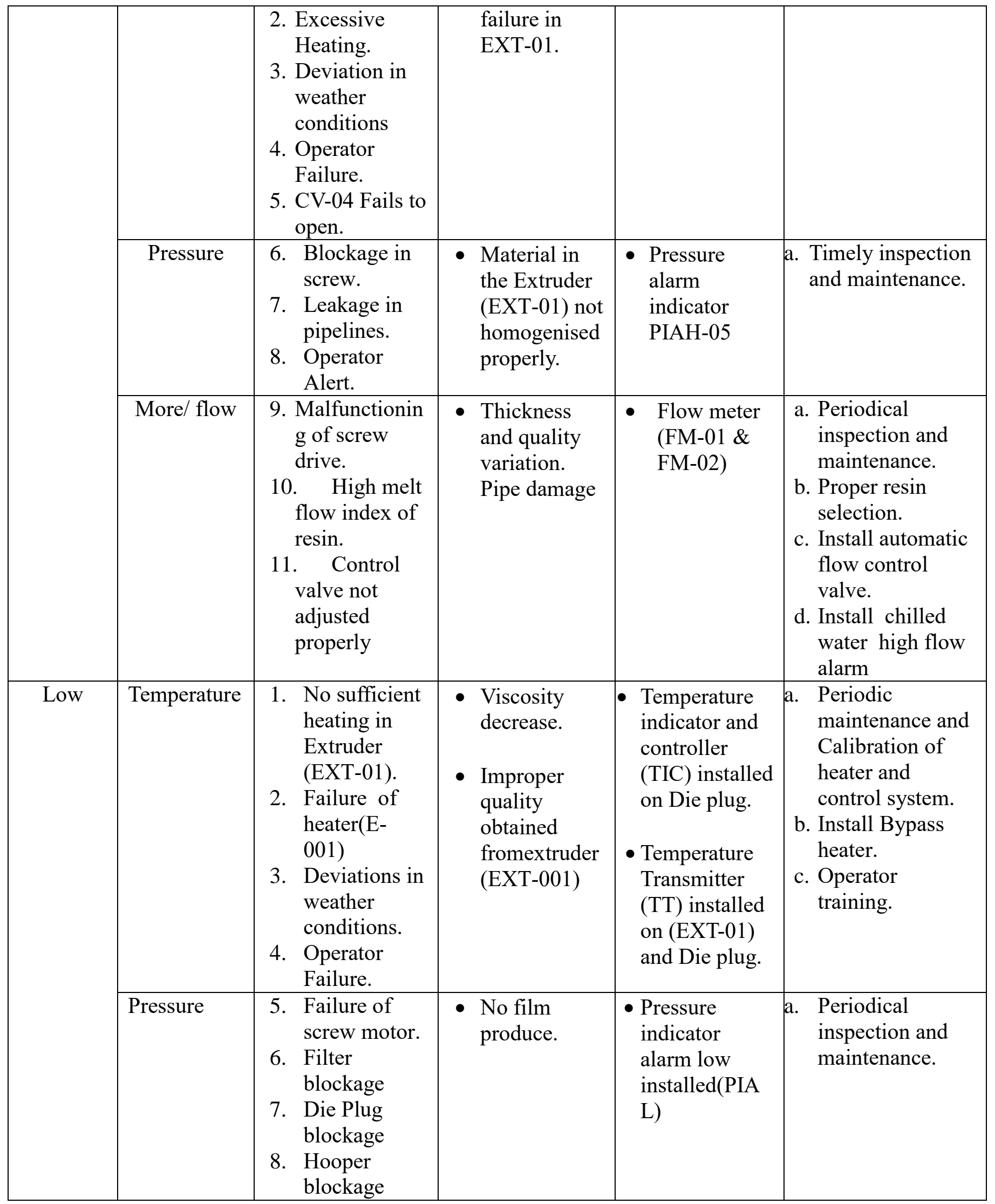




\begin{tabular}{|c|c|c|c|c|c|}
\hline Reverse & Flow & $\begin{array}{l}\text { 1. Malfunctionin } \\
\mathrm{g} \text { of valve }\end{array}$ & $\begin{array}{l}\text { - Product off } \\
\text { set. }\end{array}$ & $\begin{array}{l}\text { - No Safety In } \\
\text { Existing Plant }\end{array}$ & $\begin{array}{l}\text { a. Install non return } \\
\text { valve. }\end{array}$ \\
\hline $\begin{array}{c}\text { As well } \\
\text { as }\end{array}$ & Impurities & $\begin{array}{l}\text { 1. Presence of } \\
\text { impurities in } \\
\text { the raw } \\
\text { material from } \\
\text { feed } \\
\text { hopper(F-001) }\end{array}$ & $\begin{array}{l}\text { - Feed not } \\
\text { homogenised } \\
\text { properly. } \\
\text { - Choking in } \\
\text { the extruder. } \\
\text { - Blocking of } \\
\text { Die plug. } \\
\text { - Film } \\
\text { hardened. }\end{array}$ & $\begin{array}{l}\text { Quality } \\
\text { control lab } \\
\text { available to } \\
\text { check the } \\
\text { polypropyle } \\
\text { ne } \\
\text { granulesof } \\
\text { CPP and } \\
\text { catalyst. }\end{array}$ & $\begin{array}{l}\text { a. Regular } \\
\text { monitoring of } \\
\text { raw material } \\
\text { from quality lab } \\
\text { is required. } \\
\text { b. Follow standard } \\
\text { SOP. } \\
\text { c. Ensure standard } \\
\text { quality of raw } \\
\text { material. }\end{array}$ \\
\hline
\end{tabular}

\section{CONCLUSION}

The above detailed study proved that HAZOP is one of the best tool for the identification of hazards in plastic manufacturing unit. The operational problems / deviations of the process variables from the design intent variables as per the Piping and Instrumentation diagram (P\&ID) shown in Fig.1. On the basis of which a summarized HAZOP sheetwas presented in Table. 2

A total of 9 deviations of the process parameters were identified using guidewords. Similarly, 19 causes of deviations and about 18 consequences were highlighted. Out of which $33 \%$ of the consequences were related to the product in terms of its production and quality, $38 \%$ were related to the equipment and $5 \%$ were related to the surrounding and personnel. Moreover, existing safety control measures includes 9 different measures installed and practiced by the company. Finally, 17 recommendations were suggested.

Major hazards may occur mostly in the extruder and rotating machines of packaging industry. These hazards can be minimized by proper training of the staff as per the recommendations given in this HAZOP study. Moreover, the alarms and safety switches should be checked periodically (through proper testing methods) during the production of plastic films. All the measure role in reduction of hazards and safety of product, plant and personnel.

\section{REFERENCES}

A. Kania, M. Spilka, R. Nowosielski. Feb 2011. "Analysis of industrial threats on the chosen example." Archieves of Material Science and Engineering 117-124.

Aspin all, P. March, 2006. "HAZOPs and human factors. In HAZARDSXIX - Process Safety and Environmental Protection." Symposium Series 151, IChemE, Manchester, UK, 28-30 . Manchester, UK, 28-30 .

BorghiB.Fabiano, R.PastorinoF.CurròM.Del. Proceedings of the 10th International Symposium, 19-21 June 2001, Stockholm, Sweden. "T9-17 - A combined approach to improve safety performance on existing process plants. Practical application according to Seveso II." Loss Prevention and Safety Promotion in the Process Industries 1407-1418.

"British Standard BS: IEC61882:2002 (2002) Hazard and operability studies (HAZOP studies)- Application Guide British Standards Institution, This British Standard reproduces verbatim IEC 61882:2001 and implements it as the UK national standard."

Calixto, E. n.d. "The safety integrity level as Hazop Risk consistence. The Brazilian risk analysis study case, Risk, Reliability and Societal Safety, Aven\&Vinnem (eds.), Taylor \& Francis Group, London ISBN 978-0-415-44786-7." 629634.

June 14- 18, 2004. "Decision Support System using HAZOP results." 7th International Conference on Probabilistic Safety Assessment and Management, PSAM7 - ESREL 04. Berlin, Germany.

Dunjó, J., Fthenakisb, V., Juan A. Vílcheza, J. A. 2010. "Hazard and operability (HAZOP) analysis. A literature review." Journal of Hazardous Materials, 173 19-32.

Faisal I. Khan, S. A. Abbasi. 1998. "Techniques and methodologies for risk analysis in chemical process industries." Journal of Loss Prevention in the Process Industries 11 261-277.

Jinsong Zhaoa, Lin Cui b, Lihua Zhao b, Tong Qiua, Bingzhen Chena. 2009. "Learning HAZOP expert system by case-based reasoning and ontology." Elsevier Computer and Chemical Engineering 371-378. 
Jordi DUNJÓ DENTI, 2010,NEW TRENDS FOR CONDUCTING HAZARD \& OPERABILITY (HAZOP) STUDIES IN CONTINUOUS CHEMICAL PROCESSES, PhD Thesis submitted to the Universitat Politècnica de Catalunya

Netta Liin Rossinga, Morten Lindb, Niels Jensenc, Sten Bay Jørgensen. 2009. "A functional HAZOP methodology." Computers and Chemical Engineering 34 (2010) 244-253 (Elsevier) 244-253.

A. Kania*, M. Spilka, R. Nowosielski. Feb 2011. "Analysis of industrial threats on the chosen example." Archieves of Material Science and Engineering 117-124.

Aspin all, P. March, 2006. "HAZOPs and human factors. In HAZARDSXIX - Process Safety and Environmental Protection." Symposium Series 151, IChemE, Manchester, UK, 28-30 . Manchester, UK, 28-30 .

BorghiB.Fabiano, R.PastorinoF.CurròM.Del. Proceedings of the 10th International Symposium, 19-21 June 2001, Stockholm, Sweden. "T9-17 - A combined approach to improve safety performance on existing process plants. Practical application according to Seveso II." Loss Prevention and Safety Promotion in the Process Industries 1407-1418.

"British Standard BS: IEC61882:2002 (2002) Hazard and operability studies (HAZOP studies)- Application Guide British Standards Institution, This British Standard reproduces verbatim IEC 61882:2001 and implements it as the UK national standard."

Calixto, E. n.d. "The safety integrity level as Hazop Risk consistence. The Brazilian risk analysis study case, Risk, Reliability and Societal Safety, Aven\&Vinnem (eds.), Taylor \& Francis Group, London ISBN 978-0-415-44786-7." 629634.

June 14- 18, 2004. "Decision Support System using HAZOP results." 7th International Conference on Probabilistic Safety
Assessment and Management, PSAM7 - ESREL 04. Berlin, Germany.

Dunjó, J., Fthenakisb, V., Juan A. Vílcheza, J. A. 2010. "Hazard and operability (HAZOP) analysis. A literature review." Journal of Hazardous Materials, 173 19-32.

Faisal I. Khan, S. A. Abbasi. 1998. "Techniques and methodologies for risk analysis in chemical process industries." Journal of Loss Prevention in the Process Industries 11 261-277.

Jinsong Zhaoa, , Lin Cui b, Lihua Zhao b, Tong Qiua, Bingzhen Chena. 2009. "Learning HAZOP expert system by case-based reasoning and ontology." Elsevier Computer and Chemical Engineering 371-378.

Netta Liin Rossinga, Morten Lindb, Niels Jensenc, Sten Bay Jørgensen. 2009. "A functional HAZOP methodology." Computers and Chemical Engineering 34 (2010) 244-253 (Elsevier) 244-253.

S. SIKANDAR, S. ISHTIAQUE, N. SOOMRO. 2016 . "Hazard and Operability (HAZOP) study of wastewater treatment unit producing biohydrogen ." Sindh Univ. Res. Jour. (Sci. Ser.) Vol. 48 (1): 131-136

Shagufta I. ,Suriya J.,Shumaila S., 2017,Hazop Study on Oil Refinery Waste Water Treatment Plant in Karachi,SSRN, 1-7

S. SIKANDAR, S. ISHTIAQUE, N. SOOMRO. 2016 . "Hazard and Operability (HAZOP) study of wastewater treatment unit producing biohydrogen ." Sindh Univ. Res. Jour. (Sci. Ser.) Vol. 48 (1): 131-136.

Zhaoa, L. C. b. L. Z. b. T. Q. B. C. Jinsong. 2009. "Learning HAZOP expert system by case-based reasoning and ontology." Elsevier Computer and Chemical Engineering 371-378. 